\section{Partially insulated cutting instruments for hybrid endoscopic submucosal dissection - the Flat Adenoma Resection Instruments (FARIn)}

The endoscopic resection of colorectal polyps that are limited to the mucosa is a well established procedure. Nevertheless, modern imaging technology and screening programs have increased the detection of benign but large ( $>20 \mathrm{~mm}$ ) polyps.
In flat laterally spreading tumors (LST), especially the nongranular (NG) type, the rate of submucosal invasion is found to be as high as $39 \%(34 \%-44 \%)$ [1]. For this reason a resection in one piece is mandatory [2].
We report on the resection of a $25-\mathrm{mm}$ flat rectal LST-NG in a 60-year-old patient who was admitted to the Klinikum Augsburg after screening colonoscopy ( $\bullet$ Fig. 1 ). Examination with a high definition colonoscope (CF-HQ 190I; Olympus Medical Systems, Tokyo, Japan) demonstrated a Sano Type II, pit pattern IIIs lesion.

We decided to use two newly developed devices, the Flat Adenoma Resection Instruments (Endox-Feinmechanik GmbH, Bad Urach, Germany). Submucosal injection was performed using a mixture of saline, epinephrine $(1: 100000)$, glycerol
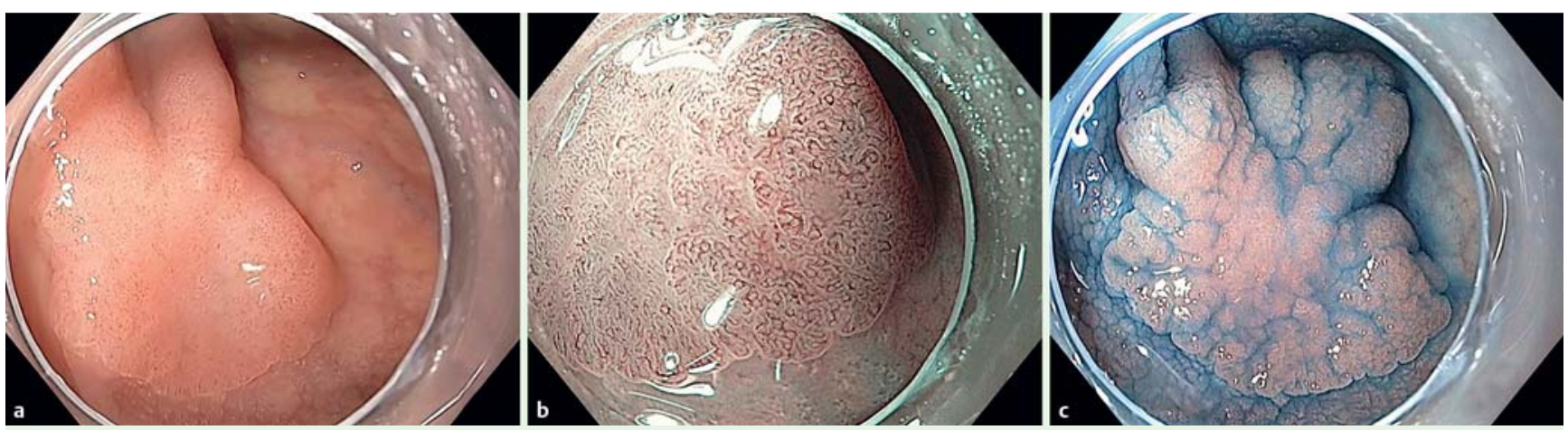

Fig. 1 Rectal laterally spreading tumor-nongranular type. a The tumor during screening colonoscopy. b Narrow-band imaging with a high definition colonoscope demonstrated a Sano Type II lesion. c After spray application of indigo carmine solution, a surface pit pattern Ills was diagnosed.
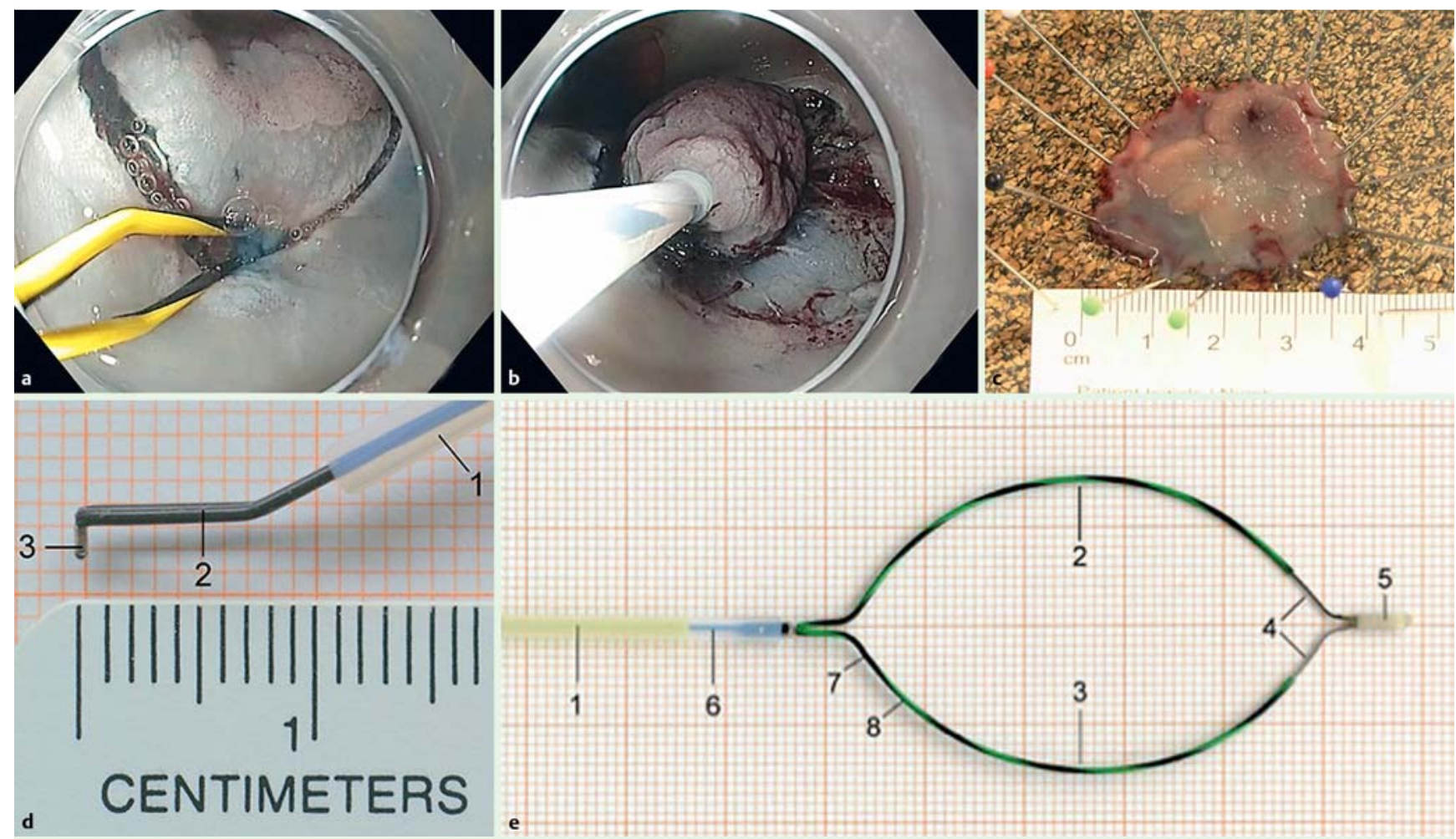

Fig. 2 Resection of the rectal tumor using the Flat Adenoma Resection Instruments (FARIn; Endox-Feinmechanik GmbH, Bad Urach, Germany). a, d Hybrid endoscopic submucosal dissection using the FARIn Type I: $1=$ catheter sheath; $2=$ the rhomboid-shaped and electrically isolated section; $3=$ the 1 -mm tooth at the distal end, used for circular incision (a). b, e The specimen could be resected using the partially insulated snare (FARIn Type C): $1=$ catheter sheath; $2,3=$ electrically isolated section of the device; $4=$ the $15-\mathrm{mm}$ cutting wire at the distal tip of the snare; $5=$ the tip of the snare is isolated in order to protect the organ wall from injury; 7,8 =The colored markings on the snare allow the cutting speed to be visualized when the snare is closed. $\mathbf{c}$ Resected specimen mounted onto cork, showing the adenoma in the center of the mucosa. 


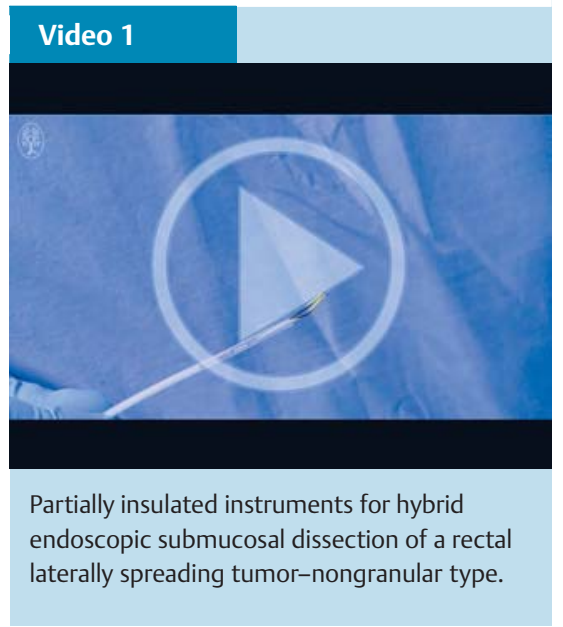

(10\%), and a small amount of indigo carmine solution. Circumferential incision was performed using the FARIn Type I, a rhomboid-shaped device with a small 1-mm cutting tooth at the distal tip. A high frequency generator (VIO 300 D; Erbe, Tübingen, Germany) was configured to AUTO CUT $300 \mathrm{~W}$ and FORCED COAG $30 \mathrm{~W}$. After circumferential incision, the specimen could be resected en bloc using the FARIn Type $C$, a symmetric snare with a cutting wire length of $15 \mathrm{~mm}$ ( $\bullet$ Fig. 2, Video 1 ).

The histopathological examination showed an adenoma with high grade dysplasia, and an adherent submucosal layer to a depth of $>1000 \mu \mathrm{m}$ under the entire lesion ( $\bullet$ Fig.3).

In summary, the FARIn instruments allowed the en bloc resection of a large $(>20 \mathrm{~mm})$ LST-NG with adherent submucosal layer $(>1000 \mu \mathrm{m})$, which meets the specimen requirements for pathological complete resection (R0).

Endoscopy_UCTN_Code_TTT_1AQ_2AD

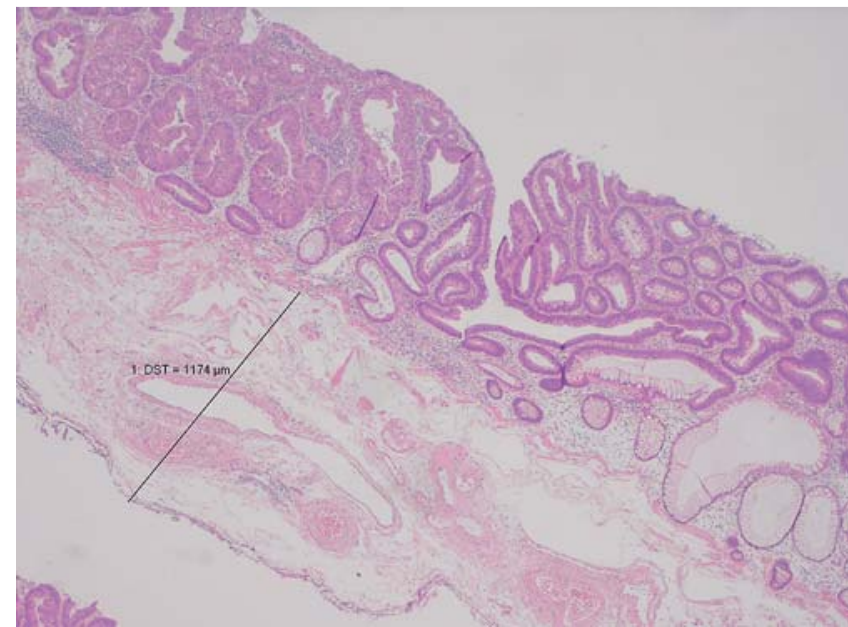

Fig. 3 The histopathological examination showed an adenoma with high grade dysplasia in the center of the lesion and an adherent submucosal layer of $>1000 \mu \mathrm{m}$ in depth (DST). Complete (R0) circumferential resection of the lesion was achieved (hematoxylin and eosin $\times 20$ ).

Competing interests: Dr. Farin is the inventor of the FARIn devices.

Stefan K. Gölder ${ }^{1}$, Tina Schaller ${ }^{2}$, Guenter Farin ${ }^{3}$, Helmut Messmann', Andreas Probst ${ }^{1}$

${ }^{1}$ Department of Internal Medicine III, Klinikum Augsburg, Augsburg, Germany

${ }^{2}$ Institute of Pathology, Klinikum Augsburg, Augsburg, Germany

${ }^{3}$ FARIN Research, Tübingen, Germany

\section{References}

1 Yamada M, Saito Y, Sakamoto $T$ et al. Endoscopic predictors of deep submucosal invasion in colorectal laterally spreading tumors. Endoscopy 2016; 48: 456-464

2 Pimentel-Nunes P, Dinis-Ribeiro M, Ponchon T et al. Endoscopic submucosal dissection: European Society of Gastrointestinal Endoscopy (ESGE) guideline. Endoscopy 2015; 47 : $829-854$
Bibliography

Dol http://dx.doi.org/

10.1055/s-0042-109058

Endoscopy 2016; 48: E218-E219

(c) Georg Thieme Verlag KG

Stuttgart · New York

ISSN 0013-726X

\section{Corresponding author}

Stefan K. Gölder, MD

Department of Internal Medicine III

Klinikum Augsburg

86156 Augsburg

Germany

Fax: +49-821-4003331

stefan.goelder@klinikum-augsburg.de 